\title{
PLATELET SEROTONIN AND NORMAL HAEMOSTASIS
}

\author{
BY \\ H. E. HUTCHISON, J. M. STARK, AND J. A. CHAPMAN \\ From the Department of Haematology, University of Glasgow, and \\ Glasgow Royal Mental Hospital
}

(RECEIVED FOR PUBLICATION OCTOBER 30, 1958)

Serotonin, or 5-hydroxytryptamine (Rapport, 1949), the physiological function of which has not yet been established, is a powerful vasoconstrictor. Carried in the blood by the platelets (Humphrey and Jaques, 1954; Udenfriend and Weissbach, 1954) and released from them as clotting occurs (Zucker and Borrelli, 1955), it has frequently been suggested (Stewart and Zucker, 1913 ; Reid, 1943 ; Stefanini and Dameshek, 1955) that it may be concerned in the mechanism of haemostasis.

Recently it has been shown, however, that the platelets (and indeed the other body depots) can be deprived of their 5-hydroxytryptamine (5HT) by the action of the active alkaloids of Rauwolfia serpentina. The platelets not only lose the 5HT they carry but also their ability to take up any further 5HT, either in vivo or in vitro (Hardisty, Ingram and Stacey, 1956 ; Carlsson, Shore, and Brodie, 1957), yet no overt haemorrhagic tendency is met with clinically. Also Weiner and Udenfriend (1957) and Haverback, Dutcher, Shore, Tomich, Terry, and Brodie (1957) have studied, in considerable detail, the haemostatic mechanism in patients receiving reserpine and have failed to demonstrate any abnormality. This finding is of such fundamental importance that a further survey extending these observations seems desirable, and this we now present.

\section{Methods and Materials}

Twelve manic-depressive patients were studied. Control observations were first made upon six before treatment with reserpine began. Thereafter, all received for varying periods (none less than 14 days) a daily oral dose of $1.5 \mathrm{mg}$. "serpasil" (Ciba).

Standard Investigations. - These included : bleeding time (Duke's method), silicone clotting time (Biggs and Macfarlane, 1957), Hess's test, platelet count, prothrombin time (Quick's one-stage), prothrombin consumption index, and thromboplastin generation test (Biggs and Macfarlane, 1957).

The following additional observations were made:

Platelet 5HT Content.-This was assayed on rat colon treated with atropine after the method of
Dalgliesh, Toh, and Work (1953), the extracts being made according to the method of Hardisty and Stacey (1955). The 5HT content is expressed as $\mu \mathrm{g}$. free base $/ 10^{\circ}$ platelets.

Plasma Clot Retraction-The platelet count of citrated platelet-rich plasma was adjusted to approximately 250,000 per c.mm. by the addition of platelet-free plasma. Five millilitres of this standardized plasma were placed in a siliconed graduated centrifuge tube and a weighted thread lowered into it. One hundred units of thrombin topical (Parke Davis), as $0.1 \mathrm{ml}$. of a $1,000 \mathrm{unit} / \mathrm{ml}$. solution, were then added and, after being tilted to mix, the mixture was incubated for one hour at $37^{\circ} \mathrm{C}$. The threaded clot was then withdrawn and its volume determined by reading the volume of the residual serum. With normally functioning platelets (unless the plasma fibrinogen content is abnormally high) the clot volume is $10 \%$ or less of the original plasma volume. This method of measuring the retraction was preferred as it eliminates the effect of variation in the packed cell volume.

Capillary Response to Injury.-This was measured by a method after Macfarlane (1941). Under the dissecting microscope, single capillaries of the nailbed were pierced by a short fine tungsten wire mounted in a glass rod and the response noted. With practice it was found possible to do this without the aid of a micro-manipulator. The glass fibres used by the original author were found to be difficult and time consuming to prepare. A fibre fine enough for use lacked the rigidity to penetrate the skin and more time was spent preparing glass fibres than observing the reactions of the capillaries. $A \frac{5}{1,000}$ in. or $\frac{10}{1,000}$ in. (125 $\mu$ and $250 \mu$ approximately) tungsten wire can be brought to the required degree of fineness and sharpness simply by heating in a bunsen flame.* The shaft of the needle obtained from $-\frac{2}{1,000}$ in. wire was found to be insufficiently strong. The skin was cleared with cedarwood oil and the best illumination was obtained from a highly intense source of green

*We are indebted to Mr. J. T. Lloyd, Department of Natural Philosophy, Glasgow University, for this method of preparing fine Phires. 
light. The examination is carried out with success only in fingers where the cuticle has been allowed to grow naturally up the nail.

Platelet Adhesiveness. - Three millilitres of plateletrich plasma, which had been collected with a siliconed system and kept at $4^{\circ} \mathrm{C}$. during all manipulations, were placed in a $15 \mathrm{ml}$. siliconed centrifuge tube with a silicone rubber stopper, the tube revolving on a "matburn"* mixer at 33 revolutions per minute in a refrigerator at $4^{\circ} \mathrm{C}$. The time taken for the platelet count to drop to half its initial figure was taken as a measure of the stickiness, the counts being performed at 30-minute intervals. The normal range of "half-time" by this method is one and a half to three and a half hours.

Thromboplastin Generation Test with Platelet Dilutions. - The thromboplastin generation test, having initially been carried out with a platelet concentration of $1 \times 10^{6} / \mathrm{c} . \mathrm{mm}$., was repeated with serial 1 in 2 dilutions of the platelet suspension. All other components of the system were standardized over the whole series of tests and controls, the only variables being the different subjects' platelets in their several dilutions. It was, therefore, appropriate to compare the performance in the generation of thromboplastin of the platelets from different donors. In a series of 21 normals, no effect on thromboplastin generation was found until the platelet suspension was diluted to 1 in 8 or more. In three cases this dilution test was also carried out with platelet suspensions to which had been added synthetic serotonin in a strength of $0.5 \mu \mathrm{g} . / 10^{9}$ platelets.

\section{Results}

Hess's test, prothrombin times, platelet adhesiveness, and clot retraction showed no change from normal after the treatment with reserpine.

Capillary Response to Injury. - The responses in the patients given reserpine as in the controls were normal, i.e., in all patients capillaries were found which vanished for 20 minutes or more after injury. As Macfarlane (1941) described, occasional capillaries were also noted which disappeared only momentarily or were only partially obliterated by irregular constrictions. Bleeding for more than the usual four or five seconds, which is of diagnostic significance in some forms of non-thrombocytopenic purpura, did not take place.

Thromboplastin Generation Tests.-No change was found in the generation of thromboplastin after the giving of reserpine. Dilution of the platelet suspension only affected generation when 1 in 8 or more. The addition of synthetic serotonin to the platelet suspension in no way affected generation.

The other findings are listed in the Table.
TABLE

\begin{tabular}{|c|c|c|c|c|c|}
\hline Case & $\begin{array}{c}\text { Platelets } \\
\left(10^{3} /\right. \\
\text { c.mm. })\end{array}$ & $\begin{array}{c}\text { Bleeding } \\
\text { Time } \\
\text { (min.) }\end{array}$ & $\begin{array}{c}\text { Silicone } \\
\text { Clotting } \\
\text { Time } \\
\text { (min.) }\end{array}$ & $\begin{array}{c}\text { Pro- } \\
\text { thrombin } \\
\text { Con- } \\
\text { sumption } \\
\text { Index }\end{array}$ & $\begin{array}{c}\text { 5HT } \\
(\mu \mathrm{g} . \text { Free } \\
\left.\text { Base } 10^{9}\right)\end{array}$ \\
\hline $\begin{array}{r}\text { I (a) } \\
\text { (b) } \\
\text { II (a) } \\
\text { (b) } \\
\text { III (a) } \\
\text { (b) } \\
\text { IV (a) } \\
\text { (b) } \\
\text { V (a) } \\
\text { (b) } \\
\text { VI (a) } \\
\text { (b) } \\
\text { VII (b) } \\
\text { VIII (b) } \\
\text { IX (b) } \\
\text { X (b) } \\
\text { XI (b) } \\
\text { XII (b) }\end{array}$ & $\begin{array}{l}355 \\
320 \\
320 \\
280 \\
320 \\
340 \\
290 \\
280 \\
210 \\
165 \\
335 \\
320 \\
305 \\
280 \\
230 \\
330 \\
225 \\
310\end{array}$ & $\begin{array}{l}2 \\
1 \frac{1}{2} \\
2 \frac{1}{2} \\
2 \frac{1}{2} \\
2 \frac{1}{2} \\
2 \\
3 \\
3 \\
2 \\
2 \\
2 \\
2 \\
2 \frac{1}{2} \\
3 \\
3 \\
3 \\
2 \\
2\end{array}$ & $\begin{array}{l}21 \\
22 \\
22 \\
22 \\
24 \\
22 \\
18 \\
18 \\
20 \\
22 \\
24 \\
24 \\
23 \\
21 \\
22 \\
19 \\
19 \\
19 \frac{1}{2}\end{array}$ & $\begin{array}{r}5 \\
8 \\
3 \\
7 \\
10 \\
9 \\
3 \\
14 \\
2 \\
10 \\
3 \\
9 \\
13 \\
2 \\
25 \\
4 \\
11 \\
2\end{array}$ & $\begin{array}{l}\mathbf{0} 59 \\
\text { Nil } \\
0 \cdot 51 \\
\text { Nil } \\
0771 \\
\text { Nil } \\
0 \cdot 45 \\
\text { Nil } \\
0 \cdot 54 \\
\text { Nil } \\
\text { 0.39 } \\
\text { Nil } \\
,, \\
,, \\
,, \\
,, \\
,, \\
,,\end{array}$ \\
\hline
\end{tabular}

(a) = Pre-treatment. (b) $=$ Post-treatment.

\section{Discussion}

The fact that $5 \mathrm{HT}$ is released from platelets during clotting suggests that it may take part in haemostasis normally. If so, a lack of 5HT might be expected to reduce the efficiency of the mechanism and an excess perhaps to enhance it.

While a transitory excess of serotonin, produced by intravenous administration, has apparently resulted in a decreased bleeding time in certain animals (Correll, Lyth, Long, and Vanderpoel, 1952), this is as likely to have been due to generalized vasoconstrictor action as to a purely local one at the site of injury. Only an evanescent and much less striking reduction in the bleeding time has been described in man after intravenous serotonin (Stefanini and Magalini, 1956) and no such findings have been recorded in cases of carcinoidosis.

Lack of 5HT, on the other hand, has not prolonged the bleeding time at all in the patients given reserpine investigated either by ourselves or others and this surprising finding seems to exclude 5HT from being concerned in the vasoconstriction of haemostasis. Estimation of the bleeding time involves injury both to capillaries and to larger vessels with muscular walls. According to Reid (1943) human capillaries are not susceptible to the action of the serum vasoconstrictor, and our direct observations show that capillary constriction following trauma can occur in the absence of 5HT. Muscular-walled vessels, however, do respond to the action of the serum vasoconstrictor (Reid, 1943 ; Zucker, 1947). Lack of 5HT might therefore have been expected to lessen their response and so prolong the bleeding time. Against this Zucker (1947) has shown that trauma 
alone will cause such vessels to contract. She noted that contraction followed injury of muscular-walled vessels in rat mesentery, even in thrombocytopenic animals where no platelet plug formed and where, therefore, there could have been no release of 5HT. From all these findings it seems that release of $5 \mathrm{HT}$ is not essential for the effective contraction of an injured vessel.

Although evidence is lacking that 5HT is related to physiological haemostasis by virtue of its vasoconstrictor activity, platelets have other functions in haemostasis and it has to be considered whether these might be altered by the absence of 5HT brought about by reserpine. Fenichel and Seegers (1955) have noted that clots of diluted platelet-poor bovine plasma retracted when serotonin was added in adequate concentration, but we found no diminution in clot retraction in the standardized platelet-rich plasma when the platelets had been freed of their 5HT; nor was intrinsic platelet adhesiveness altered. Although reserpine so intimately affects the platelets as to release all their 5HT this had no demonstrable effect on their contribution to thromboplastin generation either, their activity being undiminished even at a considerable dilution. Furthermore the normal prothrombin consumption indices indicate that the second stage of coagulation is not materially affected by the lack of 5HT. Lastly, it has been shown (Correll et al., 1952) that the presence of 5HT does not accelerate the third stage of coagulation, namely, the conversion of fibrinogen into fibrin. Our conclusion is that the removal of 5HT from the blood of a normal person causes no haemostatic defect, and this finding is in keeping with clinical observations and experience in disorders of the blood (Hardisty and Stacey, 1957). Recently, however, Jaques, Fisher, and Ashwin (1958) have reported that the superimposition of stress $(10 \%$
$\mathrm{NaCl}$ intraperitoneally) on rabbits given reserpine or of adrenalectomy in rats given reserpine provoked a haemorrhagic death; the significance of this finding is not clear.

\section{Summary}

Twelve patients whose platelets had been freed of 5-hydroxytryptamine by the administration of reserpine showed no demonstrable defect in their haemostatic mechanism. From this it appears that 5-hydroxytryptamine plays no part in normal haemostasis.

We are indebted to Dr. Angus McNiven for his permission to carry out these investigations on patients under his care; to Professor D. F. Cappell for helpful criticism and advice in the preparation of this paper ; to Mr. L. Nicolson, F.I.M.L.T., and Miss P. Cassidy, B.Sc., for technical assistance.

\section{REFERENCES}

Biggs, R., and Macfarlane, R. G. (1957). Human Blood Coagulation and Its Disorders, 2nd ed., Appendix IV. Blackwell Scientific Publications, Oxford.

Carlsson, A., Shore, P. A., and Brodie, B. B. (1957). J. Pharmacol. exp. Ther., 120, 334.

Correll, J. T., Lyth, L. F., Long, S., and Vanderpoel, J. C. (1952). Amer. J.' Physiol., 169, 537.

Dalgliesh, C. E., Toh, C. C., and Work, T. S. (1953). J. Physiol. (Lond.), 120, 298.

Fenichel, R. L., and Seegers, W. H. (1955). Amer. J. Physiol., 181, 19.

Hardisty, R. M., and Stacey, R. S. (1955). J. Physiol. (Lond.), 129, 24P.

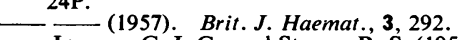
Ingram, G. I. C., and Stacey, R. S. (1956). Experientia (Basel), 12, 424 .

Haverback, B. J., Dutcher, T. F., Shore, P. A., Tomich, E. G.; Terry, L. L., and Brodie, B. B. (1957). New Engl. J. Med., 256, 343.

Humphrey, J. H., and Jaques, R. (1954). J. Physiol. (Lond.), 124, 305. Jaques, L. B., Fisher, L. M., and Ashwin, J. (1958). Seventh Congress of the International Society of Blood Transfusion, p. 255

Macfarlane, R. G. (1941). Quart. J. Med., 10, 1.

Rapport, M. M. (1949). J. biol. Chem., 180, 961.

Reid, G. (1943). Med. J. Aust., 2, 244.

Stefanini, M., and Dameshek, W.(1955). The Hemorrhagic Disorders, p. 33. Grune and Stratton, New York.

- and Magalini, S. I. (1956). A.M.A. Arch. intern. Med., 98, 23

Stewart, G. N., and Zucker, T. F. (1913). J. exp. Med., 17, 152.

Udenfriend, S., and Weissbach, H. (1954). Fed. Proc., 13, 412.

Weiner, M., and Udenfriend, S. (1957). Circulation, 15, 353.

Zucker, M. B. (1947). Amer. J. Physiol., 148, 275.

and Borrelli, J. (1955). J. appl. Physiol., 7, 425 